\title{
Feasibility and Predictability of Perioperative PET and Estrogen Receptor Ligand in Patients with Invasive Breast Cancer
}

\author{
Mary L. Gemignani ${ }^{1}$, Sujata Patil ${ }^{2}$, Venkatraman E. Seshan ${ }^{2}$, Michelle Sampson ${ }^{1}$, John L. Humm ${ }^{3}$, Jason S. Lewis ${ }^{4}$, \\ Edi Brogi ${ }^{5}$, Steven M. Larson ${ }^{4}$, Monica Morrow ${ }^{1}$, and Neeta Pandit-Taskar ${ }^{4}$ \\ ${ }^{1}$ Breast Service, Department of Surgery, Memorial Sloan-Kettering Cancer Center, New York, New York; ${ }^{2}$ Department of \\ Epidemiology and Biostatistics, Memorial Sloan-Kettering Cancer Center, New York, New York; ${ }^{3}$ Department of Medical Physics, \\ Memorial Sloan-Kettering Cancer Center, New York, New York; ${ }^{4}$ Department of Radiology, Memorial Sloan-Kettering Cancer Center, \\ New York, New York; and ${ }^{5}$ Department of Pathology, Memorial Sloan-Kettering Cancer Center, New York, New York
}

The presence of estrogen receptor (ER) in breast cancer is a prognostic indicator for both disease-free and overall survival. $16 \alpha-{ }^{18} \mathrm{~F}$-fluoro- $17 \beta$-estradiol $\left({ }^{18} \mathrm{~F}\right.$-FES) with PET is a noninvasive test for evaluation of ER expression and has been used for predicting response to endocrine therapy in patients with ER-positive metastatic breast cancer. The purpose of this study was to correlate ${ }^{18} \mathrm{~F}-\mathrm{FES} \mathrm{PET}$ and ER expression in patients with primary, operable breast cancer. Methods: Forty-eight patients were prospectively enrolled in an institutional review board-approved protocol and signed an informed consent form. All patients had undergone ${ }^{18}$ F-FES PET preoperatively. Clinical characteristics, tumor characteristics, and treatment outcomes were recorded. Immunohistochemical analysis for ER and progesterone receptor (PgR) percentage expression (46 surgical, 2 core biopsy specimens) was performed. ${ }^{18} \mathrm{~F}$-FES PET standardized uptake value (SUV) of the breast lesion was correlated with percentage immunohistochemistry ER and PgR expression. ${ }^{18} \mathrm{~F}-\mathrm{FES}$ PET SUV was quantified, with a value of 1.5 or more considered positive, and ER and PgR was quantified, with $1 \%$ or more considered positive. Formalin-fixed paraffin-embedded tissue was available for 44 patients (42 surgical, 2 core biopsy specimens). We used a microarray platform, and estrogen-related gene expression data (ESR1, ESR2, and PGR) were compared with ${ }^{18} \mathrm{~F}-\mathrm{FES}$ PET SUV (Spearman rank correlation). Tumor size, ductal histology, grade, HER2-neu overexpression, $\mathrm{PgR}$ expression, estradiol level, body mass index (BMI), and lean BMI were compared with ${ }^{18} \mathrm{~F}$-FES PET uptake using univariate and multivariate analysis. Results: Forty-eight patients completed our protocol, and 2 patients did not undergo surgery because bone metastases were identified preoperatively on ${ }^{18} \mathrm{~F}$ FES PET. Eighty-three percent of our patients were stage I or II, with a median tumor size of $1.9 \mathrm{~cm}$. Forty-one patients underwent a sentinel node biopsy. Twenty-one patients had nodal involvement. ${ }^{18} \mathrm{~F}$-FES PET identified 5 patients with axillary nodal uptake (median SUV, 3.0; range, 1.7-6.9). These 5 patients had ER-positive breast cancer, and all had more than 4 positive nodes at the time of axillary node dissection. ${ }^{18} \mathrm{~F}$-FES PET SUV was associated with immunohistochemistry ER expression. The sensitivity and specificity of the ${ }^{18} \mathrm{~F}-\mathrm{FES}$ PET for the breast lesion were 0.85

Received Aug. 31, 2012; revision accepted Apr. 23, 2013

For correspondence contact: Mary L. Gemignani, Breast Service, Department of Surgery, Memorial Sloan-Kettering Cancer Center, 300 E. 66th St. New York, NY 10065.

E-mail: gemignam@mskcc.org

Published online Aug. 22, 2013.

COPYRIGHT (c) 2013 by the Society of Nuclear Medicine and Molecular Imaging, Inc. and 0.75 , respectively. Estrogen and progesterone gene expression (ESR1, ESR2, and PGR) was not associated with ${ }^{18} \mathrm{~F}-\mathrm{FES}$ PET SUV (Spearman rank correlation). We found a significant correlation between ${ }^{18} \mathrm{~F}$-FES PET SUV and tumor size $(P=0.0015)$ but not with ductal histology, grade, HER2-neu overexpression, $\mathrm{PgR}$, estradiol, BMI, or lean BMI (logistic regression). ER expression $(P<0.001)$ and tumor size $(P<0.0001)$ were significant on multivariate regression analysis. Conclusion: ${ }^{18} \mathrm{~F}-\mathrm{FES}$ PET SUV correlated with ER immunohistochemistry expression but not gene expression in our patients with early breast cancer. We found that size of primary tumor was significantly associated with ${ }^{18} \mathrm{~F}-\mathrm{FES}$ PET SUV. ${ }^{18}$ F-FES PET is highly predictive for metastatic disease and helped in the identification of patients with metastatic disease in a preoperative setting.

Key Words: PET imaging; breast cancer; estrogen receptor; ligand

J Nucl Med 2013; 54:1697-1702

DOI: 10.2967/jnumed.112.113373

$\mathbf{T}$ he presence of estrogen receptor (ER) in breast cancer is an important prognostic indicator for both disease-free survival and overall mortality in breast cancer. The presence of ER or progesterone receptor $(\mathrm{PgR})$ is required for the use of endocrine therapy, making it one of the most important predictive factors in breast cancer management (1).

Currently, the ER status of a breast tumor is assessed through an immunohistochemistry assay performed on thin sections of tumor tissue (2). However, this method has high and consistent rates of intralaboratory and interlaboratory variability, which in turn makes it difficult to determine the true rates of ER tumor expression. Also, there is intrinsic heterogeneity of receptor content within the same lesion, as well as variations in receptor status among the primary and metastatic sites $(3,4)$. Immunohistochemistry is the method currently used for making clinical therapy decisions at most centers. However, the presence of the ER receptor in a tumor is not predictive of a functional ER. This is evident in that not all patients with ER-positive breast cancers respond to endocrine therapy (5).

$16 \alpha-{ }^{18} \mathrm{~F}$-fluoro-17 $\beta$-estradiol $\left({ }^{18} \mathrm{~F}\right.$-FES) PET is a noninvasive test that can simultaneously measure the in vivo delivery and binding of estrogens, and thus ER expression, at multiple sites 
(6). Multiple studies have validated ${ }^{18} \mathrm{~F}$-FES PET uptake as a predictor of response to endocrine therapy in patients with locally advanced or metastatic breast cancer (7-11).

The purpose of this study was to correlate ${ }^{18} \mathrm{~F}-\mathrm{FES}$ PET and ER expression in patients with primary, operable breast cancer.

\section{MATERIALS AND METHODS}

This ${ }^{18}$ F-FES study was performed under the authority of title 21 of Code of Federal Regulations part 361.1 and was approved by the Memorial Sloan-Kettering Cancer Center Radioactive Drug Research Committee and institutional review board.

Eligible patients were enrolled during the preoperative surgical consultation and gave informed, written consent. Eligibility criteria included women with intact, histologically confirmed invasive breast cancer at least $1 \mathrm{~cm}$ in size. Ineligibility criteria included a prior breast cancer diagnosis, known active infection, autoimmune or inflammatory disease, prior radiation therapy to the affected breast, chemotherapy (including neoadjuvant chemotherapy), and prior endocrine therapy.

Serum estradiol levels were measured at the time of preoperative testing or within $30 \mathrm{~d}$ before surgery. Estradiol measurements were performed by our clinical laboratory using the RIA Coat-a-Count test (Siemens Healthcare Diagnostics).

Immunostaining for ER and PgR was performed on one 5- $\mu \mathrm{m}-$ thick tissue section processed from a formalin-fixed, paraffinembedded tumor tissue block (46 surgical and 2 core biopsy specimens) with $6 \mathrm{~F} 11$ monoclonal antibody for ER and IE2 antibody for PgR using the Benchmark automated system (Ventana).

Immunohistochemistry ER and PgR expression was the percentage of tumor cells with positively staining nuclei as reported by one of the authors in our study, who also procured the tumor tissue for both immunohistochemistry analysis and microarray analysis.

The commercially available Illumina DASL expression microarray platform (Cancer Panel TMv1; Illumina), which is optimized for gene expression analysis from formalin-fixed, paraffin-embedded tissue, was used for this study. This platform contains 502 cancerrelated genes with unique probe groups for 3 different sites per gene and uses DASL technology. We selected the estrogen-related genes (ESR1, ESR2, and PGR) for our analysis. Formalin-fixed, paraffin-embedded tissue was available for 44 patients (42 surgical and 2 core biopsy specimens) for the microarray analysis. Clinical characteristics, tumor characteristics, and treatment outcomes were recorded.

\section{${ }^{18}$ F-FES PET}

The synthesis of ${ }^{18} \mathrm{~F}$-FES was based on previously reported methods $(12,13)$. The ${ }^{18} \mathrm{~F}$-FES precursor and chemical standard were purchased from ABX Advanced Biochemical Compounds GmbH. All drug preparations were checked before release for appearance, radiochemical identity, $\mathrm{pH}$, radiochemical purity, chemical purity, and pyrogenicity, and were shown to conform to the set acceptance criteria before human administration. Postrelease sterility testing was performed and was shown to conform to the set acceptance criteria in all cases. All patients received an injection of 185-296 MBq (5-8 $\mathrm{mCi})$ of ${ }^{18} \mathrm{~F}-\mathrm{FES}$. The exact time of injection and net dose were recorded. Scans consisted of a whole-body PET/CT examination (3 min per bed position) from the lower neck to the pelvis at 30 min after injection to obtain general information on the biodistribution. This scan was followed by a single 15-min spot view (or in some patients, 2 fields of view) of the chest that included the area of the primary tumor so as to obtain more counts and thereby increase the limits of detectability for the smaller lesions. The total time from injection to completion of imaging was about $90 \mathrm{~min}$. All patients were imaged on a Discovery LS or DSTE PET/CT scanner (GE Healthcare).

All patients underwent ${ }^{18} \mathrm{~F}$-FES PET preoperatively. The images were evaluated prospectively by the study's 2 nuclear medicine physicians, who were masked to the results of imaging modalities, such as breast MR imaging and mammography, but not to CT, which was used for coregistration. Grading of the results as positive or negative was based on visualization of foci of uptake suggestive of active tumor involvement. A scan was determined to be positive if focal uptake was seen in an area in at least 2 planes and was not at a site of physiologic uptake. Findings were also considered positive if uptake in an area of nonphysiologic accumulation had a standardized uptake value (SUV) of 1.5 or greater. All such sites of abnormal activity in the breast, axillae, mediastinum, or other distant organs, such as the lung, liver, or bones, or in other sites, were noted.

Images were analyzed in 3 ways: a semiquantitative analysis was performed by placing the regions of interest in areas of abnormality and determining SUV normalized to body weight; the tumor-tonontumor ratio was determined for each site by placing volumetric

TABLE 1

Patient Characteristics

\begin{tabular}{|c|c|c|}
\hline Characteristic & $n$ & Median \\
\hline Female & 48 & \\
\hline Age (y) & 48 & 50 (range, 26-77) \\
\hline Premenopausal & 29 & \\
\hline Estradiol level (pg/mL) & 48 & 25 (range, 10-479) \\
\hline Weight $(\mathrm{kg})$ & 48 & 68 (range, 48-122) \\
\hline BMI $\left(\mathrm{kg} / \mathrm{m}^{2}\right)$ & 48 & 25 (range, 18-43) \\
\hline Lean BMI $\left(\mathrm{kg} / \mathrm{m}^{2}\right)$ & 48 & 21 (range, 15-37) \\
\hline Tumor size $(\mathrm{cm})$ & 45 & 1.9 (range, 0.9-7.0) \\
\hline \multicolumn{3}{|l|}{ Histology } \\
\hline Ductal, mixed ductal & 44 & \\
\hline Lobular & 4 & \\
\hline ER-positive & 40 & \\
\hline PgR-positive & 33 & \\
\hline HER2-neu & 5 & \\
\hline \multicolumn{3}{|l|}{ Histologic grade } \\
\hline Unknown & 5 & \\
\hline Grade 2 & 7 & \\
\hline Grade 3 & 36 & \\
\hline \multicolumn{3}{|l|}{ Nuclear grade } \\
\hline Unknown & 11 & \\
\hline Grade 2 & 21 & \\
\hline Grade 3 & 16 & \\
\hline \multicolumn{3}{|l|}{ Stage } \\
\hline I & 18 & \\
\hline II & 22 & \\
\hline III & 6 & \\
\hline IV (bone) & 2 & \\
\hline Surgery & 46 & \\
\hline $\begin{array}{l}\text { Breast-conserving } \\
\text { surgery (\%) }\end{array}$ & $23(50 \%)$ & \\
\hline Mastectomy (\%) & $23(50 \%)$ & \\
\hline $\begin{array}{l}\text { Sentinel node } \\
\text { biopsy (\%) }\end{array}$ & $41(89 \%)$ & \\
\hline \multicolumn{3}{|l|}{$\begin{array}{l}\text { Lymph node } \\
\text { metastasis (\%) }\end{array}$} \\
\hline 0 & $25(54 \%)$ & \\
\hline $1-3$ & $16(35 \%)$ & \\
\hline$\geq 4$ & $5(11 \%)$ & \\
\hline
\end{tabular}


TABLE 2

Adjuvant Treatment

\begin{tabular}{|cr}
\hline \multicolumn{1}{c}{ Treatment } & $n$ \\
\hline Endocrine $^{*}$ & 48 \\
\hline None & $9(19 \%)$ \\
Tamoxifen & $18(37 \%)$ \\
\hline Tamoxifen plus aromatase inhibitor & $7(15 \%)$ \\
Aromatase inhibitor & $14(29 \%)$ \\
\hline Chemotherapy & 46 \\
\hline None & $7(15 \%)$ \\
\hline Adriamycin, cyclophosphamide, and taxol & $27(59 \%)$ \\
Cyclophosphamide, methotrexate, and & $10(22 \%)$ \\
fluorouracil & \\
Other & $2(4 \%)$ \\
Radiation & $25(54 \%)$ \\
\hline
\end{tabular}

*Includes 2 patients who did not undergo surgery.

regions of interest on the tumor using the anatomic CT dataset; and identical regions of interest were drawn in a background area (contralateral breast or other normal soft tissue). The ratio of tumor radioactivity to background radioactivity was recorded.

\section{Statistical Analysis}

Paired $t$ test comparison of ER and ${ }^{18} \mathrm{~F}-\mathrm{FES}$ PET SUV was performed with cutoffs for positivity defined as at least $1 \%$ for ER and at least 1.5 SUV for ${ }^{18}$ F-FES PET. Gene ER and PgR expression and ${ }^{18}$ F-FES PET SUV were compared with Spearman rank correlation. The relationships between serum estradiol levels, tumor size, histology, grade, PgR expression, body mass index (BMI), lean BMI, and continuous ${ }^{18}$ F-FES PET SUV were explored using linear regression or ANOVA as appropriate. Multivariate analysis of tumor size, ER percentage, and ductal histology with ${ }^{18}$ F-FES PET SUV was performed.

\section{RESULTS}

Forty-eight patients completed our protocol, and 2 patients did not undergo surgery because bone metastases were identified preoperatively on ${ }^{18} \mathrm{~F}$-FES PET.

Table 1 demonstrates the clinical and pathologic characteristics of our study group. The median age of the patients was 50 $\mathrm{y}$, and most patients $(29[60 \%])$ were premenopausal. The median estradiol level was $25 \mathrm{pg} / \mathrm{mL}$, and only 7 patients reported using hormone replacement therapy at the time of estradiol level measurement. The median BMI was $25 \mathrm{~kg} / \mathrm{m}^{2}$, and the median lean BMI was $21 \mathrm{~kg} / \mathrm{m}^{2}$. Most patients were stage I or II (40 [83\%]), with a median tumor size of $1.9 \mathrm{~cm}$. Fortyfour patients $(92 \%)$ had invasive ductal histology (ductal and mixed ductal/lobular).

Twenty-three patients (50\%) had undergone mastectomy, and 23 patients, breast-conserving surgery. Forty-one of 46 patients (89\%) had undergone sentinel node biopsy with a combination of blue dye and ${ }^{99 \mathrm{~m}} \mathrm{Tc}$-sulfur colloid on the day of or day before surgery or with blue dye alone on the day of surgery. Six patients had received a ${ }^{99 \mathrm{~m}} \mathrm{Tc}$-sulfur colloid injection on the same day as the ${ }^{18} \mathrm{~F}$-FES injection and had undergone lymphoscintigraphy before receiving the ${ }^{18} \mathrm{~F}-\mathrm{FES}$ injection.

Twenty-one of 46 patients $(46 \%)$ had nodal involvement. ${ }^{18} \mathrm{~F}$ FES PET uptake in the axilla was identified in 5 patients (median SUV, 3.0; range, 1.7-6.9). All 5 of these patients had ER-positive

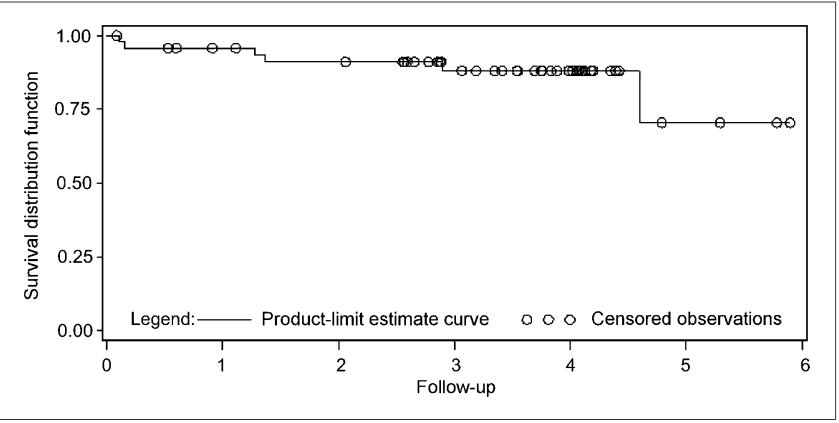

FIGURE 1. Kaplan-Meier survival analysis for study cohort. Median follow-up was 3.7 y (range, 0.1-5.9 y), with 3-y median disease-free survival of 0.88 (95\% confidence interval, $0.73-0.95$ ).

breast cancer and more than 4 positive nodes at the completion of axillary node dissection. The mean number of positive lymph nodes was 22 (range, 7-39), with the largest node measuring an average of $2.2 \mathrm{~cm}$ (range, $1.2-4.2 \mathrm{~cm}$ ). There were 16 patients with no ${ }^{18}$ F-FES PET uptake in the axilla: 6 had immunohistochemistry-only cells, 5 had 1 positive node, and the remaining 5 had 2 positive nodes ( 3 patients) or 3 positive nodes ( 2 patients), with the largest node measuring an average of $1.5 \mathrm{~cm}$ (range, $0.8-4.5)$.

${ }^{18} \mathrm{~F}$-FES uptake was identified in 4 bone lesions; 3 patients had undergone fine-needle aspiration biopsy, which confirmed metastasis, and 2 were identified preoperatively and did not have surgery; 1 patient was identified at follow-up. An additional patient had an ${ }^{18} \mathrm{~F}$-FES SUV of 6.6 in a rib lesion, and biopsy revealed fibrous dysplasia. Three of the 4 bone metastases had been assessed for ER and $\operatorname{PgR}$ immunohistochemistry expression, with ER immunohistochemistry values of 5\%, 90\%, and $90 \%$ and PgR immunohistochemistry values of $0 \%, 90 \%$, and $50 \%$, respectively.

Most patients were treated with adjuvant chemotherapy (85\%) or endocrine therapy (81\%) (Table 2). Oncotype DX (Genomic Health) test results were available in 10 patients, with a median score of 19 (range, 6-46). Seven patients had a distant recurrence; 2 of these had concomitant local recurrence, and 1 patient died of disease (median follow-up, $3.7 \mathrm{y}$; range, 0.1-5.9 y). The Kaplan-Meier survival curve is shown in Figure 1. The 3 -y disease-free interval was 0.88 (95\% confidence interval, $0.73-0.95)$.

The sensitivity of the ${ }^{18}$ F-FES PET SUV as compared with immunohistochemistry ER expression was 0.85 , and specificity was 0.75 . The positive predictive value was 0.94 , and the negative predictive value was 0.50 (Table 3 ). The receiver-operatingcharacteristic curve for ER expression is shown in Figure 2, with

TABLE 3

Comparison of Immunohistochemistry ER Expression and ${ }^{18} \mathrm{~F}-\mathrm{FES}$ PET SUV

\begin{tabular}{cccc}
\hline \multirow{2}{*}{$\begin{array}{c}\text { Immunohistochemistry } \\
\text { ER }\end{array}$} & $\begin{array}{c}18 \mathrm{~F}-\mathrm{FES} \\
\mathrm{PET}\end{array}$ & $\begin{array}{c}{ }^{18} \mathrm{~F}-\mathrm{FES} \\
\mathrm{PET}\end{array}$ & \\
& SUV $<1.5$ & SUV $\geq 1.5$ & Total \\
\hline$<1 \%$ & 6 & 2 & 8 \\
$\geq 1 \%$ & 6 & 34 & 40 \\
Total & 12 & 36 & 48 \\
\hline
\end{tabular}




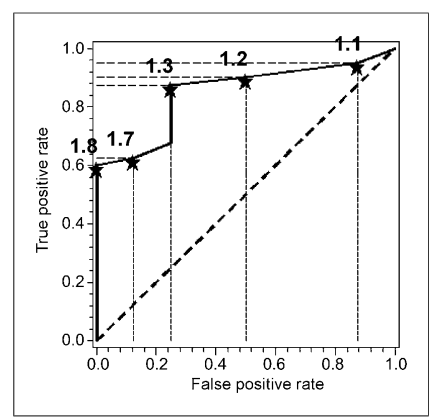

FIGURE 2. Receiver-operatingcharacteristic curve for ER expression vs. ${ }^{18}$ F-FES PET SUV ( $n=48$; stars with associated number identify ${ }^{18} \mathrm{~F}$-FES PET SUV at that point on receiver-operatingcharacteristic curve).

SUV and tumor size $(P=0.0015)$ but not HER2-neu overexpression $(P=0.58)$, estradiol $(P=0.60), \mathrm{PgR}$ expression $(P=0.44)$, BMI $(P=0.15)$, lean BMI $(P=0.14)$, tumor type $(P=0.60)$, histologic grade $(P=0.29)$, or nuclear grade $(P=$ $0.67)$. On multivariate regression analysis, tumor size $(P<$ $0.0001)$ and immunohistochemistry ER expression $(P<0.001)$ were significant.

We had 6 patients who had immunohistochemistry tumor expression of at least 1\% (median, 90\%; range, 5\%-95\%) and an ${ }^{18}$ F-FES PET SUV of less than 1.5. Four of these 6 patients had stage I disease, and thus it is likely the breast lesions were too small to be visualized on ${ }^{18} \mathrm{~F}$-FES PET. The median tumor size of these 6 patients was $1.2 \mathrm{~cm}$ (range, $0.9-2.0 \mathrm{~cm}$ ).

Figure 3 shows an ${ }^{18} \mathrm{~F}$-FES scan with intense uptake in the left breast lesion corresponding to an ER-positive breast cancer. Five patients in our study underwent additional ${ }^{18} \mathrm{~F}-\mathrm{FDG}$ PET at the time of the ${ }^{18} \mathrm{~F}$-FES PET. Figure 4 shows the ${ }^{18} \mathrm{~F}-\mathrm{FDG}$ and ${ }^{18} \mathrm{~F}-\mathrm{FES}$ scans of a patient with ER-negative cancer. Figure 5 shows an ${ }^{18} \mathrm{~F}$-FES scan of a patient with locally advanced, ERpositive breast cancer with multiple sites of disease in the breast and regional lymph node metastases.

\section{DISCUSSION}

Studies have previously validated ${ }^{18} \mathrm{~F}$-FES PET uptake as a measure of ER expression in breast cancer $(6,14)$. Mintun et al. demonstrated a high correlation between in vitro tumor ER concentrations measured using the radioligand method and ${ }^{18} \mathrm{~F}$ FES uptake in the primary lesion $(6,8)$. Peterson et al. compared
ER expression measured by in vitro immunohistochemistry with ${ }^{18}$ F-FES uptake and noted a high correlation with ${ }^{18}$ F-FES uptake and ER expression in the primary lesion (14). Dehdashti et al. (9) found a correlation of $88 \%$ between in vitro ER assays and ${ }^{18}$ F-FES PET SUV.

Most of the studies to date include patients with locally advanced or metastatic breast cancer. Our study correlates ER expression in tumor tissue with ${ }^{18} \mathrm{~F}$-FES uptake in patients with early-stage operable breast cancer. We found a correlation with immunohistochemistry ER expression but not with gene expression. There was a significant association with ${ }^{18} \mathrm{~F}-\mathrm{FES}$ uptake and size of primary tumor, likely accounting for the lower sensitivity we saw in our study group as compared with prior published work $(8,14)$.

Peterson et al. (11) examined potential factors that would influence ${ }^{18} \mathrm{~F}$-FES PET uptake and found an association with BMI but not lean BMI. In that study, an association with sex hormone-binding globulin but not estradiol was noted. In our study, we explored the relationship between factors such as estradiol levels, BMI, and lean BMI and did not find an association. Like Mintun et al. (6), we also did not find an association with PgR expression. Additionally, we evaluated grade, histology, and HER2-neu overexpression and did not find any association.

${ }^{18} \mathrm{~F}-\mathrm{FES}$ PET has also been shown to measure ER expression in multiple sites of disease. Studies have demonstrated ${ }^{18} \mathrm{~F}$-FES uptake in axillary nodes and distant sites of disease $(6,8)$.

Similarly, in our study population, we found that ${ }^{18} \mathrm{~F}$-FES PET detected disease in distant sites (bone) and in axillary lymph nodes. In the axilla, small-volume disease was not identified with ${ }^{18}$ F-FES uptake. All 5 patients with uptake in the axilla had more than 4 nodes involved with disease, suggesting that a larger burden of disease was necessary for ${ }^{18}$ F-FES PET uptake to be demonstrated in the axilla.

The heterogeneity of the ER expression of multiple sites of disease was demonstrated in a study by Kumar et al. (15) that compared ${ }^{18}$ F-FDG PET and ${ }^{18}$ F-FES PET and showed multiple sites of ${ }^{18} \mathrm{~F}-\mathrm{FDG}$ activity without corresponding ${ }^{18} \mathrm{~F}$-FES uptake (15). Mortimer et al. (10) found that in a study of 21 patients with ER-positive breast cancer, 5 demonstrated no ${ }^{18} \mathrm{~F}$-FES uptake, thus showing that ${ }^{18} \mathrm{~F}-\mathrm{FES}$ PET can reveal the functional status of the ER that is not accessible through in vitro ER measurement. Similarly, Linden et al. (16) found that 6 of 47 patients with ERexpressing breast cancer had one or more sites of metastatic disease that did not have ${ }^{18} \mathrm{~F}$-FES uptake.

Our study had 6 patients with strongly ER-expressing primary tumors that did not show significant ${ }^{18} \mathrm{~F}$-FES uptake. Four of the 6 patients had stage I disease, and small tumor size likely contributed to this discordant finding. Overall, the correlation between ER expression and ${ }^{18} \mathrm{~F}$-FES PET in our study was not as strong as previously reported in other studies, and we found no association with ER gene expression. Given the discrepancy in association between ${ }^{18} \mathrm{~F}$-FES PET SUV and immunohistochemistry ER expression versus ER gene expression, it is possible that significant tumor heterogeneity for ER expression is present even in this group of patients with untreated,
FIGURE 3. ER-positive left breast cancer. Axial ${ }^{18} \mathrm{~F}-\mathrm{FES}$ image (A) shows intense uptake (arrow) in left breast lesion, corresponding to 2.3-cm lesion seen on CT (C) and confirmed by ${ }^{18}$ F-FES PET/CT image (B). Tumor was ER-positive, with SUV of 3.5. early breast cancers.

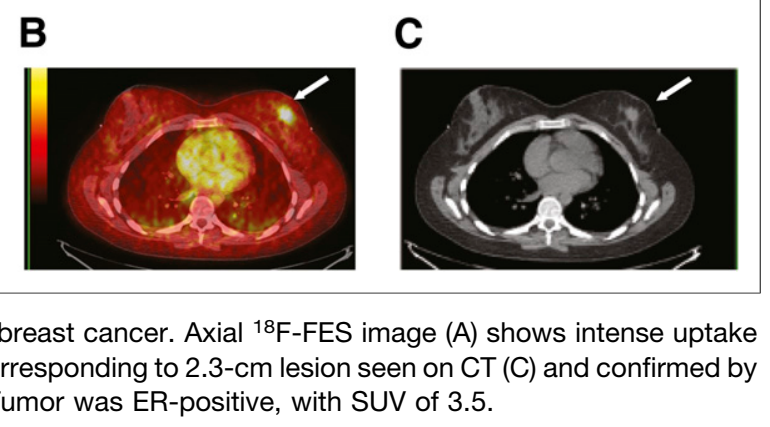




\section{A}

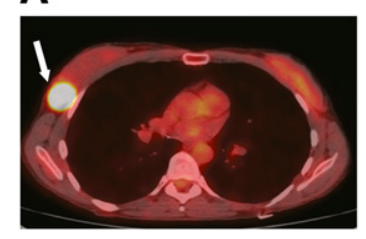

B
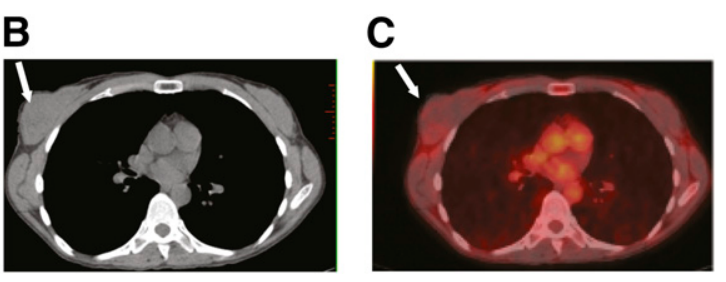

FIGURE 4. ER-negative right breast cancer. Intense uptake (arrow) is seen in right breast lesion on ${ }^{18} \mathrm{~F}-\mathrm{FDG} \mathrm{PET} / \mathrm{CT}$ scan (A), corresponding to lesion seen on CT (B); no uptake is seen on ${ }^{18} \mathrm{~F}$-FES PET/CT scan $(\mathrm{C})$.

One of the most important potential applications of this technology appears to be in predicting response to endocrine therapy. Several studies have validated the use of ${ }^{18} \mathrm{~F}$-FES PET in predicting response. Mortimer et al. (17) showed that the level of ${ }^{18} \mathrm{~F}$-FES uptake predicted response to tamoxifen in locally advanced and metastatic breast cancer. Linden et al. (16) showed the ability of ${ }^{18}$ F-FES PET to predict response to endocrine therapy with aromatase inhibitors. Dehdashti et al. (9) showed that metabolic flare assessed through ${ }^{18} \mathrm{~F}-\mathrm{FES}$ and ${ }^{18} \mathrm{~F}-$ FDG SUV can be predictive of response to endocrine therapy with aromatase inhibitor and fulvestrant. Linden et al. (7) recently

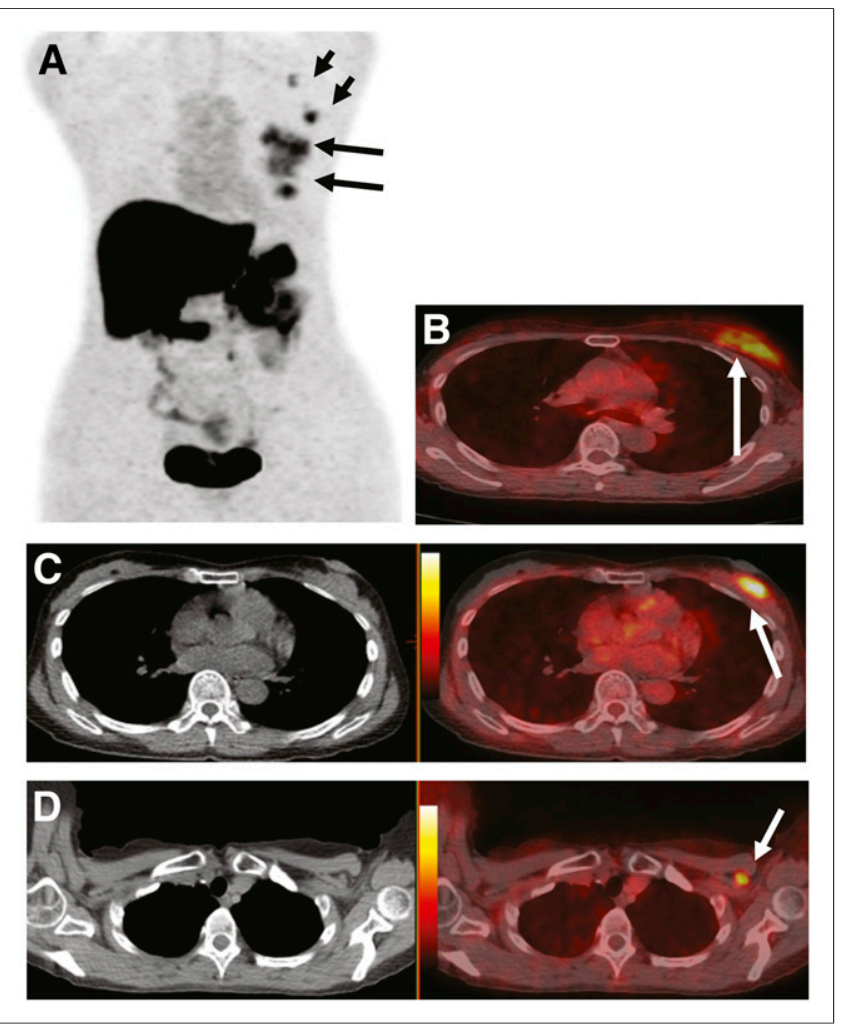

FIGURE 5. Locally advanced ER-positive breast cancer. (A) On maximum-intensity-projection ${ }^{18} \mathrm{~F}$-FES image, intense uptake is seen in large left breast mass (long arrows). Smaller mass is also seen inferiorly (short arrows). (B) ${ }^{18} \mathrm{~F}-\mathrm{FES}$ PET/CT image shows uptake with SUV of 5.7 in large breast mass (arrow). (C and D) Smaller inferior mass (arrow) is also seen on ${ }^{18} \mathrm{~F}-\mathrm{FES} \mathrm{PET/CT} \mathrm{(C),}$ as is uptake in small subpectoral node and axillary node (D). Corresponding $\mathrm{CT}$ scans are shown on left. reported on a study of serial ${ }^{18} \mathrm{~F}$-FES PET in patients with metastatic breast cancer comparing aromatase inhibitor, tamoxifen, or fulvestrant and noted that tumor ${ }^{18}$ F-FES uptake decreased more with ERblocking therapies than with estrogendepleting therapies. All these studies support the use of ${ }^{18}$ F-FES PET in accurately predicting response to endocrine therapy.

Our study group predominantly comprised early-stage patients who received additional adjuvant therapies. Most received endocrine therapy $(81 \%)$ or chemotherapy $(85 \%)$ and had excellent disease-free survival. We did not find an association with ${ }^{18}$ F-FES PET SUV and outcome, but this analysis was limited, as few events occurred in our study population at this time. With further follow-up, it will be interesting to correlate the ${ }^{18} \mathrm{~F}-\mathrm{FES}$ PET SUV and outcomes in our study group.

\section{CONCLUSION}

Our study supported the existing data on the role of ${ }^{18} \mathrm{~F}-\mathrm{FES}$ PET in characterizing ER expression. In the perioperative setting, ${ }^{18}$ F-FES PET reliably identified additional sites of disease. However, our study highlighted the effects of tumor size and disease burden in imaging with ${ }^{18}$ F-FES PET and possible limitations on its role in the primary operative, early breast cancer setting.

\section{DISCLOSURE}

The costs of publication of this article were defrayed in part by the payment of page charges. Therefore, and solely to indicate this fact, this article is hereby marked "advertisement" in accordance with 18 USC section 1734. Funding for this study was provided by U.S. Department of Defense grant BC030997 (principal investigator, Mary L. Gemignani). No other potential conflict of interest relevant to this article was reported.

\section{ACKNOWLEDGMENTS}

We thank Eva Burnazi, Shangde Cai, Howard Sheh, and Calvin Lom of the MSKCC Cyclotron-Radiochemistry Core (NIH Center grant P30-CA08748) for the production of ${ }^{18} \mathrm{~F}-\mathrm{FES}$.

\section{REFERENCES}

1. Davies C, Godwin J, Gray R, et al. Relevance of breast cancer hormone receptors and other factors to the efficacy of adjuvant tamoxifen: patient-level meta-analysis of randomised trials. Lancet. 2011;378:771-784.

2. Fisher ER, Anderson S, Dean S, et al. Solving the dilemma of the immunohistochemical and other methods used for scoring estrogen receptor and progesterone receptor in patients with invasive breast carcinoma. Cancer. 2005;103:164-173.

3. Castagnetta L, Traina A, Di Carlo A, et al. Do multiple oestrogen receptor assays give significant additional information for the management of breast cancer? $\mathrm{Br} \mathrm{J}$ Cancer. 1989;59:636-638.

4. van Netten JP, Armstrong JB, Carlyle SJ, et al. Cellular distribution patterns of estrogen receptor in human breast cancer. Eur J Cancer Clin Oncol. 1988;24: 1899-1901.

5. Vollenweider-Zerargui L, Barrelet L, Wong Y, Lemarchand-Beraud T, Gomez F. The predictive value of estrogen and progesterone receptors' concentrations on the clinical behavior of breast cancer in women: clinical correlation on 547 patients. Cancer. 1986;57:1171-1180.

6. Mintun MA, Welch MJ, Siegel BA, et al. Breast cancer: PET imaging of estrogen receptors. Radiology. 1988;169:45-48. 
7. Linden HM, Kurland BF, Peterson LM, et al. Fluoroestradiol positron emission tomography reveals differences in pharmacodynamics of aromatase inhibitors, tamoxifen, and fulvestrant in patients with metastatic breast cancer. Clin Cancer Res. 2011;17:4799-4805.

8. McGuire AH, Dehdashti F, Siegel BA, et al. Positron tomographic assessment of 16 alpha- $\left[{ }^{18} \mathrm{~F}\right]$ fluoro-17 beta-estradiol uptake in metastatic breast carcinoma. J Nucl Med. 1991;32:1526-1531.

9. Dehdashti F, Mortimer JE, Siegel BA, et al. Positron tomographic assessment of estrogen receptors in breast cancer: comparison with FDG-PET and in vitro receptor assays. J Nucl Med. 1995;36:1766-1774.

10. Mortimer JE, Dehdashti F, Siegel BA, Katzenellenbogen JA, Fracasso P, Welch MJ. Positron emission tomography with 2 -[ $\left.{ }^{18} \mathrm{~F}\right]$ fluoro-2-deoxy-D-glucose and 16alpha$\left[{ }^{18} \mathrm{~F}\right]$ fluoro-17beta-estradiol in breast cancer: correlation with estrogen receptor status and response to systemic therapy. Clin Cancer Res. 1996;2:933-939.

11. Peterson LM, Kurland BF, Link JM, et al. Factors influencing the uptake of ${ }^{18} \mathrm{~F}$ fluoroestradiol in patients with estrogen receptor positive breast cancer. Nucl Med Biol. 2011;38:969-978.

12. Brodack JW, Kilbourn MR, Welch MJ, Katzenellenbogen JA. NCA 16 alpha$\left[{ }^{18} \mathrm{~F}\right]$ fluoroestradiol-17 beta: the effect of reaction vessel on fluorine-18 resolu- bilization, product yield, and effective specific activity. Int J Rad Appl Instrum [A]. 1986;37:217-221.

13. Kiesewetter DO, Kilbourn MR, Landvatter SW, Heiman DF, Katzenellenbogen JA, Welch MJ. Preparation of four fluorine-18-labeled estrogens and their selective uptakes in target tissues of immature rats. J Nucl Med. 1984;25:1212-1221.

14. Peterson LM, Mankoff DA, Lawton T, et al. Quantitative imaging of estrogen receptor expression in breast cancer with PET and ${ }^{18} \mathrm{~F}$-fluoroestradiol. $\mathrm{J} \mathrm{Nucl}$ Med. 2008;49:367-374.

15. Kumar P, Mercer J, Doerkson C, Tonkin K, McEwan AJ. Clinical production, stability studies and PET imaging with 16 -alpha- $\left[{ }^{18} \mathrm{~F}\right]$ fluroestradiol $\left(\left[{ }^{18} \mathrm{~F}\right] \mathrm{FES}\right.$ in ER positive breast cancer patients. J Pharm Pharm Sci. 2007;10(suppl):256s$265 \mathrm{~s}$.

16. Linden HM, Stekhova SA, Link JM, et al. Quantitative fluoroestradiol positron emission tomography imaging predicts response to endocrine treatment in breast cancer. J Clin Oncol. 2006;24:2793-2799.

17. Mortimer JE, Dehdashti F, Siegel BA, Trinkaus K, Katzenellenbogen JA, Welch MJ. Metabolic flare: indicator of hormone responsiveness in advanced breast cancer. J Clin Oncol. 2001;19:2797-2803. 